\title{
CUIDADO COM PACIENTES E FAMÍLIAS QUE VIVENCIAM O PROCESSO DE MORTE: REPRESENTAÇÕES SOCIAIS DO ENFERMEIRO
}

\author{
CARE FOR PATIENTS AND FAMILIES WHO LEAVE THE DEATH PROCESS: SOCIAL \\ REPRESENTATIONS OF THE NURSE
}

\author{
Amanda Regina da Silva Gois ${ }^{\mathrm{a}^{*}}$, Fatima Maria da Silva Abrão ${ }^{\mathrm{b}^{\star}}$, Inacia Satiro Xavier França ${ }^{\mathrm{c}^{*}}$ \\ amanda_regina137@hotmail.coma , fatimabrao@gmail.com ${ }^{\mathrm{b}}$, inácia.franca@hotmail.comc \\ Universidade de Pernambuco. Campus Petrolina*, Universidade Estadual da Paraíba**
}

Data de recebimento do artigo: 03/12/2018

Data de aceite do artigo: 18/02/2019

\begin{abstract}
RESUMO
Introdução: Enfermeiros cuidam da pessoa, família e coletividade, sendo assim, quando o sujeito inicia a vivencia do processo de morte a família também passa a ser alvo cuidar desses profissionais. Objetivo: Compreender e analisar as representações sociais dos enfermeiros sobre o cuidado com pacientes e famílias que vivenciam o processo de morte. Materiais e Métodos: Trata-se de estudo de campo, exploratório, qualitativo de representações sociais. Realizado em unidades oncológicas de um hospital universitário, vinte e um enfermeiros foram entrevistados, estas passaram por análise de conteúdo temático-categorial. Resultados: Emergiram da análise das falas, as seguintes unidades temáticas: 1) Cuidando do paciente em processo de morte; 2) Cuidando da família do paciente em processo de morte; 3) As relações e estratégias entre o enfermeiro, paciente e família diante do processo de morte; 4) Quando ou se é o seu familiar em processo de morte. Conclusão: $\mathbf{O}$ cuidado com a família do paciente em processo de morte é um desafio pelos diversos aspectos que envolvem. Destacando-se que a conversa, o diálogo, o respeito e o olhar introspectivo, podem mediar estas relações.
\end{abstract}

Palavras-chave: Enfermagem; cuidados de enfermagem; relações profissional-família; oncologia; morte.

\section{ABSTRACT}

Introduction: Nurses take care of the person, family and community, so when the subject begins to experience the death process, the family also becomes the target of caring for these professionals. Objective: To understand and analyze the social representations of nurses about the care of patients and families who experience the death process. Materials and Methods: This is a field, exploratory, qualitative study of social representations. Performed in oncological units of a university hospital, twenty-one nurses were interviewed, these went through analysis of thematic-categorial content. Results: The following thematic units emerged from the analysis of the speeches: 1) Caring for the patient in the process of death; 2) Caring for the family of the patient in the process of death; 3) The relationships and strategies between the nurse, patient and family before the death process; 4) When or if it is your relative in the process of death. Conclusion: Caring for the family of the patient in the process of death is a challenge for the various aspects involved. Stressing that the conversation, the dialogue, the respect and the introspective look, can mediate these relations.

Key-word: Nursing; nursing care; professional-family relations; oncology; death. 


\section{Introdução}

Compete à enfermagem, como profissão, cuidar da pessoa, família e coletividade. Sendo assim, quando o sujeito inicia a vivência do processo de morte que envolve etapas que retomam a descoberta da doença no diagnóstico até o aparecimento dos primeiros sinais e sintomas até a exclusão da possibilidade terapêutica sob a perspectiva curativa, através do suporte tecnológicos, a família também passa a ser alvo do seu processo de trabalho. O presente estudo tem como objeto as representações sociais do enfermeiro no cuidado com pessoa/paciente e família que vivenciam o processo de morte ${ }^{1-2}$.

Considerou-se neste estudo que as etapas do processo de morte e os sentimentos experiências pelo paciente podem ser: Negação e isolamento; Raiva; Barganha; Depressão e Aceitação, que podem ser atribuídos não somente a ele, salientando-se que esses podem ainda estender-se aos demais integrantes da tríade paciente-profissional de saúde- família ${ }^{3}$.

Norteou-se este estudo partindo-se do questionamento: neste processo, a família da pessoa/ paciente também morre (vivencia o processo de morte e morrer)? Isso porque a hipótese de que essa família morre está ancorada na conformação de diversas situações que circundam a vivência do processo de morte, ou seja, uma das etapas crucias do processo de morte e talvez a mais dolorosa delas é o momento da aceitação da morte, compreender que a doença instalou-se de modo que em pouco espaço de tempo a vida como se conhece terminará.

Contudo, algumas doenças debilitam o paciente de modo que esse não toma conhecimento de sua terminalidade instalada como processo de morte propriamente dito, outros como crianças muito jovens, idosos e pessoas com déficit de conhecimento ou limitações cognitivas não conseguem ou tem limitação para compreender o processo, nesses casos a vivência da amplitude da compreensão do processo de morte recai sobre a família de forma mais intensa. Em outros casos, a família consciente da gravidade do processo, acaba por optar em não revelar ao ente querido, com objetivo de minimizar o sofrimento ${ }^{4}$.

Assim sendo, seja participando de uma ou de todas as fases do processo a família encontra-se inserida neste de forma ativa. O enfermeiro então, precisa engajar a família no planejamento e implementação do cuidado do paciente em processo de morte, como alvo do cuidado do enfermeiro, revela-se como um dos princípios fundamentais na unidade de tratamento compreendendo o paciente e sua família ${ }^{5}$.

A enfermagem ainda deve estar atenta ao cuidado pós-morte que permeiam a preparação do corpo, a possibilidade de transplantes de órgãos e tecidos, necessidade que tem significados para a família e que não deve ser negligenciada ${ }^{6}$.

Contudo, o cuidado com pacientes e famílias que vivenciam o processo de morte ainda representa um desafio para o enfermeiro. Diante disso, o presente estudo deseja questionar quais as representações do enfermeiro sob esta perspectiva, observando na prática profissional a grande preocupação dos enfermeiros com o sofrimento da família diante do processo de morte. Em vista disso, o presente estudo objetivou compreender e analisar as representações sociais dos enfermeiros sobre o cuidado com pacientes e famílias que vivenciam o processo de morte.

\section{Metodologia}

Trata-se de estudo de campo, exploratório, qualitativo, cujo o referencial teórico metodológico, as representações sociais foram instituídas diante da complexidade da problemática da pesquisa, selecionado em função das dimensões que se quer explorar ou desvendar, tendo optado-se pela abordagem descritiva do conteúdo das representações ${ }^{6}$.

Os dados foram coletados através de entrevistas do tipo semiestruturada em unidades oncológicas de um hospital universitário da cidade do Recife, Pernambuco, Brasil com vinte e um enfermeiros da Oncologia. As entrevistas foram gravadas, transcritas integralmente, procedendo-se apenas adequação à norma culta padrão da língua portuguesa, após assinatura do Termo de Consentimento Livre e Esclarecido.

Respeitou-se os princípios éticos em conformidade com a Resolução CNS 196/1996, sobre Diretrizes e Normas Regulamentadoras de Pesquisa envolvendo Seres Humanos do Ministério da Saúde (MS), em vigor no período da coleta 
dos dados, mantendo-se em consonância com o preconizado pela Resolução 466/2012 (MS), tendo sido aprovado por comitê de ética em pesquisa, através do projeto de iniciação cientifica intitulado Cotidiano Profissional: Como os enfermeiros lidam com a morte e a religiosidade em seu processo de cuidar? Sob o protocolo (CAAE) de número: 0060.0.106.000-09, o referido projeto foi financiado pelo Conselho Nacional de Desenvolvimento Científico e Tecnológico ( $\mathrm{CNPq}$ ) no período compreendido entre agosto de 2009 e agosto de 2010.

Procedeu-se a análise dos dados, sob a perspectiva da abordagem descritiva do conteúdo das representações sociais, utilizando-se a técnica de análise de conteúdo temático-categorial de Bardin obedecendo às três fases do processo: Pré-análise, exploração do material, e tratamento dos resultados (Inferência e Interpretação). Todo o processo analítico busca a identificação nas falas dos participantes do estudo, de elementos, que seja mais frequente de modo a caracterizar as unidades temáticas e as categorias ${ }^{(7)}$.

A discussão dos dados realizou-se à luz de autores essenciais que discutem a temática na área de conhecimento da enfermagem associada a teoria das representações sociais.

\section{Resultados}

Emergiram da análise das falas, as seguintes unidades temáticas: 1) Cuidando do paciente em processo de morte; 2) Cuidando da família do paciente em processo de morte; 3) As relações e estratégias entre o enfermeiro, paciente e família diante do processo de morte; 4) Quando ou se é o seu familiar em processo de morte. Disposta a seguir na apresentação e descrição dos resultados.

\section{Cuidando do paciente em processo de morte}

Esta unidade temática, apresenta-se em resposta ao questionamento que norteou o estudo, questionar quais as representações do enfermeiro referente ao cuidado com pacientes e famílias que vivenciam o processo de morte? Diante do desafio que este cuidado ainda representa para o enfermeiro em sua prática profissional, e a preocupação dos mesmos com o sofrimento da família, vivenciando o processo de morte.

Nas falas os enfermeiros representam o processo de morte do paciente sob a perspectiva da compreensão, ou da ciência que este tem ou não do instaurar do processo de morte, bem como da vigência da sua terminalidade e da instituição de um protocolo de paliação. Emergindo a categoria consciente e orientado sobre a terminalidade, descrito na fala a seguir:

"Acho que quando aquele paciente terminal que não está consciente e orientado. Aquele que não está lúcido, eu acho que ele não sente tanto, mas aquele que está consciente e orientado acho que ele sofre muito mais sabendo que está chegando a hora" (Enfermeira 05)

"[...] o paciente em estado terminal é muitas vezes um paciente sedado, por isso é muito mais difícil lidar com a família." (Enfermeira 10)

Os profissionais claramente representam que o planejamento da assistência e as diferentes relações ao lidar com este paciente em processo de morte serão direcionadas, a partir da sua consciência ou ciência da vivencia do processo e a compreensão dos significados do mesmo e das práticas a serem instituídas de enfrentamento e condutas terapêuticas. Bem como, atribuem o sofrimento à este saber.

Para estes, o nível de consciência e orientação, se em uso de sedativos e outras medicações e condutas que interverem no estado de alerta, modificam o cuidado com este paciente e os significados do próprio processo de morte.

Neste sentido, cuidar do paciente em processo de morte desvela ainda um outro aspecto, a centralização do cuidado no indivíduo-paciente. As falas destacam que os profissionais aproximam-se do paciente com mais frequência do que da família, seja como o significado por eles como apego - vínculo relacional, ou pela possibilidade de conforto e alívio do sofrimento que o processo de morte pode proporcionar para o doente, que segundo o profissional pode tornar o processo, 
de certo modo, mais fácil para o paciente. Como apresenta a categoria apego e sofrimento. Representada nas falas abaixo.

"A gente tá todo dia com o paciente, cuidando dele, e a gente se apega e sofre quando ele parte, e muitos são como se fosse da família[...](Enfermeira 20)

"[...] è mais difícil lidar com a família... porque o que ameniza pra mim é saber que hoje eles(os pacientes) não estão mais sofrendo, mas a família as vezes continua sofrendo." (Enfermeira 01)

Representa-se que a dificuldade em lidar com as famílias dos pacientes em processo de morte, relacionam-se a representação da não aceitação do processo de morte, em vigência na contemporaneidade ocidental, e os aspectos éticos, morais e de valoração deste tempo e sociedade.

"[...] as vezes o ser humano enquanto ser humano não aceita a morte, e principalmente porque é um ente querido [...]" (Enfermeira 05)

\section{Cuidando da família do paciente em processo de morte}

O cuidado com a família do paciente em processo de morte, sobre tudo do paciente oncológico é um imperativo na prática profissional do enfermeiro que desvela lacunas no preparo do profissional para este assistir, nas falas analisadas os profissionais referem que à mais dificuldade em lidar com a família do que com o paciente, estabelecendo um entrave à vivencia deste cuidado à família.

Neste contexto, a categoria famílias complicadas descreve as representações dos profissionais que compreendem o momento da comunicação com a família ou na realização de algum procedimento de enfermagem como passível à geração de conflitos.

Diante da angustia experênciada pela família, os sinais e sintomas de gravidade da doença podem gerar insegurança e até desconfiança em relação à conduta profissional, isto porque a família, mesmo quando detêm algum conhecimento na área da saúde, pode ter dificuldade em interpretar evidencias de intercorrência e necessidade de intervenção, fato este que reforça à importância da educação em saúde, mas que leva o profissional à uma situação de desconforto e até insatisfação. Principalmente em situações interpretadas como desrespeito, pelo profissional, principalmente quando a comunicação da família é realizada de modo descortês, como descreve a fala a seguir.

"Eu acho que é mais difícil lidar com a família, não é somente com paciente terminal, qualquer paciente, as vezes a família é tão complicada, tão complicada... chegamos para prestar assistência ao paciente e a família faz aquela barreira, [...], é muito chato quando a família quer ensinar você a fazer o seu trabalho, como se não confiasse em você, como se não confiasse na sua formação. A família as vezes não chega para conversar [...] O paciente, as vezes não tem nada grave, no momento. Aconteceu essa semana mesmo, um senhor, internado e a neta dele[...] de repente, começou a gritar e gritar. [...] Este comportamento dela, muito me admirou por ela ser estudante da área, para mim ela deveria ter respeitado o profissional enfermeiro, porque ela praticamente julgou que nós, não estivéssemos fazendo o nosso trabalho, como se para nós o estado e os sinais vitais do paciente não fossem relevantes. [...] É por isso que eu acho que as vezes a família atrapalha muito mais." (Enfermeira 12)

As dificuldades enfrentadas pelo enfermeiro ao lidar com a família do paciente em processo de morte, já são esperadas pelo enfermeiro. Este deve buscar posicionar-se de maneira segura e calma para que o momento de estresse da família não se torne um elemento gerador de estresse para ele próprio em sua prática e dificulte o planejamento, implementação e avaliação do cuidado de enfermagem, como discute a categoria famílias estressadas, evidenciada na seguinte fala.

"Extremamente calma! Não tem estresse nenhum, eu tento acalmar a família, se a família fica estressada, fica aquele "auê" aqui." (Enfermeira 02)

O processo de morte causa dor e sofrimento às famílias, mas conversar e preparar-se para o momento do óbito pode torná-lo um momento mais 
brando. Sabe-se que alguns membros da família estariam mais aptos à estar acompanhando este paciente, neste processo durante o internamento hospitalar. As pessoas reagem de forma diferente ao sofrimento, e à terminalidade. Para alguns estar presente é mais doloroso do que estar ausente na hora da morte, e acabam não tomando ciência da gravidade da doença do seu ente querido, seja por questões emocionais, quando sofrem demais estando presente; relacionais, quando não mantinham contato direto prévio ao adoecimento ou ainda deslocamento, quando não podem distanciar-se do trabalho ou deslocar-se devido à longa distância ou condição própria de saúde.

A categoria a seguir denominada famílias que sofrem, representa estes sofrimentos particulares de cada membro da família, as diversas formas de lidar com ele, bem como aborda as questões referentes à um preparo prévio para o acompanhamento hospitalar de paciente terminal, necessário à família a fim de permitir a elaboração de estratégias de apoio, conforto e luto por parte da equipe de enfermagem.

"[...] havia um paciente com tumor de face, em fase terminal, e deixaram com ele um filho, uma pessoa que estava totalmente desinformada quanto ao prognóstico, sendo que esse paciente tinha uma filha médica e deixaram-no com esse filho, que eu acho que não sabia que o paciente estava tão grave, já fora de possibilidade terapêutica, terminal e em paliação. E ele chorando, chamava a gente o tempo todo, que o pai dele não estava conseguindo respira [...] E acabou esse paciente indo à óbito naquele dia, com ele (o filho) sozinho sem mais ninguém da família ali com eles, o paciente morreu e ele assim chorando, com tanta gente na familia e deixam uma pessoa assim sozinha, nem estava preparado, parecia uma criança chorando! (Enfermeira 11)

Esta fala é um relato de como o enfermeiro representa a figura do familiar sobe dois pontos distintos, quando bem orientado sobre o estado clinico do paciente e aceitando a termalidade ou sem conhecimento da eminencia do processo de morte, sofrendo e angustiando-se intensamente.
AS RELAÇÕES E ESTRATÉGIAS ENTRE O ENFERMEIRO, PACIENTE E FAMÍLIA DIANTE DO PROCESSO DE MORTE

O enfermeiro prepara-se e almeja cuidar do paciente, mas costuma não estar motivado para o cuidado com a família. Por isso, as relações e estratégias para o cuidado da família do paciente em processo de morte, serão representados nesta unidade temática. Deste modo, no processo de geração e divulgação das representações os profissionais são influenciados por suas concepções, valores e experiências relacionadas ao processo de morte e morrer.

A categoria conversa/diálogo e respeito, destaca a importância de manter um relacionamento com o paciente em todas as fases do processo de morte, independente do estado ou nível de consciência do mesmo, de modo à transmitir para a família o respeito à dignidade humana presente no ato de cuidar intrinsicamente.

"Conversar com o paciente, mesmo quando achar que ele não está mais ouvindo ou entendendo, respeitando ele e a família."( Enfermeira 08)

"Acho que tem que ter diálogo. Tem que parar e escutar o paciente, mesmo na fase final ele ainda tem coisas a dizer[...] então a gente tem que parar, mesmo no corre, corre. Muitas vezes, a gente passa pelo doente e não fala. Mas, a gente tem que parar e escutar o que esse doente quer dizer, eu acho importante." (Enfermeira 05)

Salienta-se que, uma das principais estratégias representadas é trabalhar as emoções, como profissional, o enfermeiro pode aprender como se relacionar de forma ética mediante às fala, atos e escolhas proferidas por pacientes e suas famílias. A fala a seguir demonstra a essência deste ato na categoria Confiança, destacando que ao incentivar uma relação baseada na conversa - como por exemplo a negociando de horários para realização de cuidados e visitas; informação quanto a necessidade da realização de procedimentos; entre outros - e respeito, o enfermeiro conquista a confiança do paciente e família, com destaca-se.

"Confiança, ele tem que saber, que o profissional está fazendo de tudo pra amenizar o sofrimento deles (paciente e família)." (Enfermeira 17) 
Outra fala destaca a relação de confiança estabelecida no cuidado, destacando a construção de uma amizade como molde de confiança. Reafirmando que o profissional se empenha neste cuidado, pois valoriza aquela vida de maneira ímpar, de modo à despertar no indivíduo cuidado, melhores sentimentos - sentir-se valorizado, amado e respeitado.

"Assim, acho que quando mostramos para o paciente que ele pode ter-nos como amigos ele sente-se muito mais confortável, [...] assim ele percebe que quando solicitar, ele sabe que pode contar conosco. Eu acho que ele se sente melhor, quando se permite ser nosso amigo." (Enfermeira 12)

\section{QUANDO OU SE É O SEU FAMILIAR EM PROCESSO DE MORTE}

O cuidado dos enfermeiros diante do processo de morte exige mais do que conhecimentos técnicos, exige uma busca pelo autoconhecimento que moldem e transformem o cuidado, de modo a amenizar o sofrimento psíquico e emocional que o ato de repetição deste fato do cotidiano pode levar. Isto porque, como ser humano o enfermeiro, tem também uma família, repleta de pessoas a quem ama e valoriza.

Torna-se inevitável remeter-se à elas em momento de desgaste frente ao sofrimento do outro. É comum, perante o processo do morrer e, ao cuidar das famílias, que o enfermeiro se coloque no lugar do outro e se questione: e se fosse o meu familiar? ou e quando for o meu familiar? Ou ainda um questionamento de um familiar inserido no cuidado que entoa ao enfermeiro e se fosse o seu familiar? Diante destes questionamentos presentes nas falas dos sujeitos do estudo, emerge esta unidade temática.

$\mathrm{Na}$ fala a seguir, o enfermeiro, sente-se o responsável pelo cuidado em saúde da sua própria família, emergindo a categoria cuidando da própria família-elementos negativos.

“...mas, quando é nossa familia a gente sempre está perto, nós da área da saúde somos quem mais se envolve, e ficamos sabendo de tudo antes dos outros." (Enfermeira 04)

No instante que ser o primeiro a saber sobre o adoecimento do parente e/ou familiar é compre- endido com responsabilidade do enfermeiro por ele e pelos outros, isto pode acarretar uma sobre carga física, psíquica, emocional e espiritual. A fala a seguir representa que o diagnóstico a ser conhecido por um familiar não enfermeiro, não tem muitas vezes, significados prévios, mas para o enfermeiro que lida com o processo de morte em seu dia-a-dia pode clarificar uma triste trajetória no vislumbrar de um prognóstico com base nas experiências profissionais e conhecimentos técnicos-científicos, tornando muitas vezes, o sofrimento particularmente ainda mais doloroso.

"Para mim foi difícil. Porque, ela (a mãe) morreu com câncer, câncer no intestino [...] quando eu tive conhecimento do diagnóstico e eu sabia daquele processo todo... eu já trabalho já conheço como caminha, a trajetória e onde vai chegar no final. Para mim foi muito doloroso!". (Enfermeira 14)

Para o enfermeiro, e mais precisamente para o enfermeiro especialista em oncologia, ter um familiar enfrentando este adoecimento oncológico é um processo muito doloroso, simboliza trazer o sofrimento do trabalho para casa e o sofrimento de casa para o trabalho. E faz refletir sobre como lidar com o paciente. Seria a recomendação de trata-lo com a um familiar seu, a melhor estratégia? As falas à seguir polarizam este questionamento destacando as peculiaridades de tratamento oncológico, que pode tornar o paciente, família e profissionais velhos conhecidos decorrente da ampla duração do tratamento ou amigos, tornando o enfrentamento do processo de morte diferente da morte de um familiar ou amigo do enfermeiro ou até mesmo igual.

"É diferente quando você perde um ente querido seu. Tudo bem que na oncologia nos apegamos ao paciente, porque é um tratamento duradouro, que leva 2 à 3 anos, mas em relação a família, quando fala de sangue é muito difícil." (Enfermeira 12)

"Assim, aqui as pessoas que eu tive...que eu tive contato (pacientes) que vieram a falecer, se tornaram meus amigos, então daqui não tem diferença entre amigos e paciente não, são todos meus amigos." (Enfermeira 03) 
Sumarizando esta perspectiva, a fala a seguir descreve que o cuidado de enfermagem pode ser melhor empregado quando o enfermeiro não sente o mesmo pelo paciente quanto sentiria por um familiar, mas quando cuida dele e de sua família do modo como gostaria que sua própria família e amigos fossem cuidadas por outros profissionais.

"[...] eu vejo um paciente como um familiar meu, no sentido de que eu quero que ele receba o mesmo que o meu paciente receberia de mim, comparo ele neste sentido, mas quando ele morre o meu sentimento por ele não é o mesmo que fosse por um parente. (Enfermeira 11)

No mesmo contexto de que o lidar no cotidiano profissional com o processo de morte pode levar o enfermeiro ao desgaste e sofrimento, pode também, quando trabalhado, ajudá-lo a compreender o seu papel neste evento/fenômeno eminente do ciclo da vida e enfrentar melhor situações que envolvem a vida pessoal e privada. Viver a categoria enunciada nesta unidade temática, cuidando da própria família- elementos positivos, sobre uma outra perspectiva. Como descreve a fala a seguir.

"É eu acho que...minha experiência profissional me fez encarar a morte de maneira mais natural... quando eu entrei na faculdade minha avó estava muito doente, mas eu não reconheci que ela ia morrer. Eu não entendia que as pessoas morriam, nunca tinha visto um parente meu morrer e ela morreu exatamente na véspera da prova de anatomia [...], mas, comecei a entender que a morte é uma coisa natural que tem que acontecer para todo mundo e quando eu estava no sétimo período na véspera da prova de pediatria minha outra avó morreu, mas eu já tinha outra visão da morte, já via que ela era idosa, com a saúde muito desgastada [...]já tinha outra visão, já tinha visto outros pacientes morrendo. (Enfermeira 21)

\section{Discussão}

Quando um indivíduo adoece, ele não adoece sozinho toda a família adoece junto com ele. Por isso, sem dúvida, o maior avanço no cuidado ao paciente em processo de morte tem sido a compreensão holística do mesmo e a valorização dos cuidados paliativos na busca pela qualidade na assistência, oferecendo um suporte ao paciente grave e/ou portador de doença ativa e progressiva que ameace a continuidade da vida e as suas famílias ${ }^{8}$.

Discute-se neste contexto que, a teoria das representações pode proporcionar resposta aos questionamentos apontados no estudo, diante do fato de que são uma forma de conhecimento, socialmente elaborado e partilhado, que possuem objetivo prático capaz de elucidar processos cognitivos e das interações sociais, para a compreensão e construção de uma realidade comum a um dado conjunto social ${ }^{9}$.

Como é a questão da compreensão do cuidar do paciente em processo de morte, que permite desvelar o fato de representar o nível de consciência e orientação como parâmetro para conduzir as formas de lidar com o processo de morte do paciente.

Salienta-se que as representações podem ser compreendidas através de dois pressupostos formulados através do sistema de defasagem ${ }^{9}$, sendo o primeiro encorajador à esta representação, vislumbrando que pacientes clinicamente avaliados como conscientes e orientados tomam as próprias decisões e estabelecem diretamente um contato com os profissionais de saúde sobre a conduta terapêutica a ser implementada, no planejamento do cuidado ${ }^{10}$.

Este fato sem dúvida muda as formas de lidar com o processo de morte, tendo em vista que os principais agentes envolvidos neste processo serão os profissionais e pacientes. Enquanto que, no caso oposto, os familiares são os protagonistas da negociação dos processos terapêuticos e de cuidados, somente baseados em desejos e preferências previas dos pacientes, isto segundo muitas vezes relatos da própria família, que dificilmente poderão ser confirmados pelos profissionais.

O segundo pressuposto desta representação, destaca um risco ao cuidado de enfermagem integralizado, que está no fato de em algumas situações o paciente inconsciente, comatoso, torporoso, ou ainda desorientado, não ser contemplado como ser biopsicossocial e espiritual ${ }^{11}$.

Esta seria portanto, a fonte dos questionamentos, dos quais advém os estudos sobre a importância da humanização do processo de morte em 
tempos de predominância de um modelo biomédico, hospitalocêntrico e curativo ${ }^{12}$.

Já o cuidado da família do paciente em processo de morte, destaca a representação das famílias como sendo um elemento complicador. Família complicada, é uma expressão utilizada de forma rotineira pelo profissional enfermeiro, e pode ser significada como uma família que trata a equipe com desconfiança, não compreende bem as orientações, não se mostra adepto às práticas educativas e comumente, não respeita as normas institucionais, quando se trata de paciente internado ${ }^{13}$.

Outras representações destacam as pelos eventos que as cercam neste processo, como o estresse e o sofrimento, isto diante de dúvidas quanto à terapêutica, conduta medica e prognóstico, que muitas vezes não são repassadas entre os familiares, e que geram conflitos éticos e relacionais entre a equipe de enfermagem, outros profissionais de saúde e família ${ }^{14-16}$.

As representações sociais dos enfermeiros sobre o cuidado com pacientes e famílias que vivenciam o processo de morte, destacam ainda elementos quanto a relações e estratégias entre a tríade, isto porque as representações sociais são formas de ser, interpretar e interagir no mundo real, envolvendo as questões relativas aos processos de pertença social com as implicações afetivas e normativas na apropriação dos conteúdos da realidade. Representar corresponderia então, de fato ao ato ou atitude pelo qual o sujeito relaciona-se a um objeto'.

No cuidar da família, o enfermeiro deparar-se-á com questões que vão de encontro com sua própria filosofia de vida e seus valores pessoais. Ao se aproximar das famílias, poderá compreender que o cuidado envolve competências ontológicas, essenciais à maturidade e à sobrevivência da enfermagem ${ }^{15}$.

Discute-se ainda que, quando frente ao processo de morte de um familiar ou amigo, o profissional sente-se responsável por cuidar da própria família, destaca-se ainda que o medo da morte, e a dificuldade em lidar com ela presente no dia-a-dia dos profissionais, e a preferência que se tem em ignorá-la ou manter uma postura de distanciamento é escolhida por alguns profissionais como um mecanismo de autodefesa a fim de não pensar na própria morte ou na morte de alguém que ama, com um familiar ${ }^{3}$.

\section{Conclusões}

O presente estudo permitiu compreender as representações sociais dos enfermeiros sobre o cuidado com pacientes e famílias que vivenciam o processo de morte, a partir da análise de suas falas, desvelando estratégias de como lidar com o processo de morte do paciente.

A análise evidenciou que elementos clínicos que interferem no nível de consciência dos pacientes modificam o planejamento do cuidado e as formas de inclusão da família neste processo, considerando abordagens biopsicossociais e espirituais que destacam a importância da humanização.

O estudo ainda destaca, que o cuidado voltado para a família do paciente em processo de morte, é um desafio constante para a equipe de enfermagem, a ser inserido no plano terapêutico e educacional na conjuntura do seu processo de trabalho considerando os eventos que cercam este processo, como o sofrimento, o estresse e a possibilidade de conflitos éticos frente aos elementos da vulnerabilidade dos atores da tríade paciente-profissional-familiar neste processo conflituoso.

Compreende-se que as relações entre estes atores, suscitam a construção de estratégias para o desenvolvimento deste cuidado envolvendo competências emocionais, psicológicas e espirituais que permeiam desde o distanciamento como um mecanismo de autodefesa às estratégias que envolvem atitudes relacionais valorizando a conversa, diálogo e respeito; suscitando a confiança. Cuidando com foco na dignidade humana, vislumbrando à qualidade na assistência e a segurança nas práticas de saúde.

Destaca-se ainda neste estudo, que a humanização proposta não seria a do emprego do cuidado, transferindo sentimentos e emoções da vida privada para a profissional, o que pode suscitar ainda mais sofrimento. Mas propor a reflexão do cuidado voltado o indivíduo, família e a coletividade, com ênfase na educação em saúde.

\section{Referências}

1. World Health Organization. National cancer control programmes: policies and managerial guidelines. Geneva. 2002; Suppl:12-46. 
2. Rockembach JV, Casarin ST, Siqueira CHC. Morte pediátrica no cotidiano de trabalho do enfermeiro: sentimentos e estratégias de enfrentamento. Rev RENE. 2012; 11(2):20-32.

3. Kubler-Ross E. A roda da vida: memórias do viver e do morrer. 2. ed. Rio de Janeiro: Sextante; 1998

4. Silva AF, Issi HB, Motta MGB. A família da criança oncológica em cuidados paliativos: o olhar da equipe de enfermagem. Ciênc cuid saúde. 2012; 10(4): 820-27.

5. Benedetti G, Santos M. Significado do processo morte/ morrer para os acadêmicos ingressantes no curso de enfermagem. Rev gaúch enferm. 2013; 34(1):173-79.

6. Oliveira, DC. Pontuando idéias sobre o desenvolvimento metodológico das representações sociais nas pesquisas brasileiras. Rev bras enferm [online]. 2005 [cited 2015 jun 12]; 58(1):86-90. Available from: http://www.scielo.br/scielo.ph p?pid=S003471672005000100017\&script=sci_arttext.

7. Bardin L. Análise de Conteúdo procedimentos metodológicos. 70. ed. Lisboa: Edições 70; 2007.

8. Baliza MF et al. Cuidados paliativos no domicílio: percepção de enfermeiras da Estratégia Saúde da Família. Acta paul enferm [online]. 2012 [cited 2015 jan 28];25(2):138. Available from:http://www.scielo.br/scielo.php?pid= S010321002012000900003\&script=sci_arttext\&tlng=pt.

9. Jodelet D. As representações sociais. Rio de Janeiro: Eduerj; 2001. p.17-44

10. Miliorini JP et al. A família no contexto hospitalar: apreendendo os anseios e expectativas relacionadas com doença crônica. Rev RENE. 2012; 9(3): 34-6.

11. Abrão FMS, Góis ARS, Souza MSB, Araujo RA, Cartaxo CMB, Oliveira DC. Representações sociais de enfermeiros sobre a religiosidade ao cuidar de pacientes em processo de morte. Rev bras enferm. [Internet]. 2013 Oct [cited 2015 July 14] ; 66( 5 ): 730-737. Available from: http://www.scielo.br/scielo.php?script=sci_arttext\&pid=S00371672013000500014\&lng=en. http://dx.doi. org/10.1590/S0034-71672013000500014.

12. Machado JH et al. Paciente que requer cuidados paliativos: percepção de enfermeiras. Enferm foco. 2015; 4(2):15-23.

13. Silveira RA, Oliveira ICS. O cotidiano do familiar/acompanhante junto da criança com doença oncológica durante a hospitalização. Rev Rene; 2012; 12(3):134-46.

14. Ferreira NML, Andrade CS, Stuchi Z. Cuidados paliativos e família. Rev ciênc méd. 2012; 17(1):237-45.

15. Fernandes MFP, Komessu JH. Desafios do enfermeiro diante da dor e do sofrimento da família de pacientes fora de possibilidades terapêuticas. Rev Esc Enferm USP 2013; 47(1):250-7

16. Claudia L. Epelman. End-of-Life Management in Pediatric Cancer. Curr onco rep. 2012; 14(2): 191-6.

Como citar este artigo:

Gois ARS, Abrão FMS, França ISX. Processo de morte de pacientes e famílias segundo o enfermeiro. Rev. Aten. Saúde 2019;17(59):44-52. 